fewer or worse values now than in Ancient Rome or in Mediaeval times? Even in Queen Victoria's golden days, long before modern cosmology began, policemen were unable to patrol the streets of London without carrying firearms and being in pairs. At a time when only one-third of British 13-yearolds believe the Earth goes round the Sun, how many people have really had their values stripped away by science? Yet Midgley writes: "The world's new position is often felt to have astonishing moral and metaphysical consequences, such as that truth or justice has become a meaningless concept - sometimes, even more strangely, the psychological consequence that all human kindness is an illusion." No evidence is offered for this extraordinary statement. Since most people remain honest, kind and decent, one wonders what company she has been keeping: surely her philosopher colleagues cannot be that vicious.

Leaving aside the speculations of philosophers and cosmologists, it is unclear why values should be in the least affected by discoveries in physics. One cannot, as the saying goes, "get an ought from an is". Values and morality concern how we chose to spend our time, how we treat others and, one hopes, how far we try to avoid damage to future generations through maltreating the Earth. What occurs in other galaxies is irrelevant - unless, of course, intelligent beings were found there, in which case we might have to think hard about how to treat them. Midgley does not even stop to ask whether if there really is a malaise in the Western world, it might be caused by factors other than science, such as the environment of inner cities, the breaking down of the traditional roles of the different classes, increased tolerance for divergent behaviour or even television. Does she really suppose that those yobbos on Tyneside were prompted to engage in car burn-ups as a result of reading Stephen Hawking or that the violence of the $\mathrm{Ku}$ Klux Klan was inspired by too close an acquaintance with relativity theory?

Stuart Sutherland is in the Laboratory of Experimental Psychology, University of Sussex, Brighton BN1 9QG, UK.

The relationships between modern science and society are explored in two other recently published books aimed at a popular audience. In The Creative Moment, Joseph Schwartz, coauthor of Einstein for Beginners, looks at "how science made itself alien to modern culture" (HarperCollins/Jonathan Cape; $\$ 25$, £16.99). In The Science Gap, Milton A. Rothman sets about "dispelling the myths and understanding the reality of science" (Prometheus, \$24.95).

\section{Under the net}

\section{Christopher W. Petersen}

The Ecology of Fishes on Coral Reefs. Edited by Peter F. Sale. Academic: 1991. Pp. 754. \$75.00, £46.50.

CORAL reefs are one of the most diverse and productive ecosystems in the world (and also one of the most threatened). A main component of reef fauna are fishes, and those inhabiting reefs form one of the most assorted and abundant assemblages of vertebrates to be found anywhere in the world. Yet ten years ago, reviews of the ecology of fishes on coral reefs were mainly limited to arguments

\section{IMAGE UNAVAILABLE FOR COPYRIGHT REASONS}

\section{Juvenile grunts and blackbar soldierfish \\ on a 3-year-old reef in the Caribbean.}

over the relative roles of competition and chance in determining the sizes of adult fish populations. That time is over. This outstanding book marks the maturation of the field as a dynamic area of study that has successfully shed its simple early hypotheses for a rich blend of experimentally based research programmes. The volume will quickly become required reading and the main review source for reef-fish biologists, and also an essential work of reference for other interested ecologists.

Peter Sale has succeeded in bringing together a wide range of different viewpoints under one cover. The book's 20 chapters are written by a list of authors that reads like a Who's Who of reef-fish ecologists, with a blend of US workers planted firmly in the Caribbean, and Australian and New Zealand workers focusing their efforts in the Indo-Pacific, particularly on the Great Barrier Reef.

By studying different species in different places, the authors often see different factors regulating population size and community structure; so it is hardly surprising that they sometimes disagree on the importance of various processes in the ecology and evolution of reef fishes. But workers now acknowledge these differences and attempt to put their findings into perspective.

Sale has done an excellent job of balancing the contributions. The book is divided into six sections covering basic material such as the visual world, morphology, evolution and palaeontology of reef fishes; trophic relationships; larval and juvenile ecology; reproductive and life-history patterns; community organization; and fisheries and their management. Palaeontology and the management of fisheries are subjects that are not generally discussed in journals on reef-fish ecology, so the book will certainly broaden the horizons of a lot of workers in the field.

Many of the authors try to frame their findings in the wider picture of the patterns and processes they see in reeffish ecology. Several look at factors that limit local population size, but many

focus on coevolution in reef communities, from patterns of herbivory and plant defences to biogeographical and palaeontological patterns. Embedded in the chapters are plenty of research programmes that will inspire those just beginning to study reef fishes.

An area not covered that deserves more attention is the genetic structure of populations of reef fishes. Despite the meagre amount of data so far published on the subject, estimates of genetic differentiation among populations should eventually provide useful insights into biogeographical trends, fisheries management and the consequences of interspecific differences in larval biology.

Sale first shook up the ideas of many biologists in the early 1970 s when he proposed that niche partitioning was not important for reef fishes. This nonMacArthurian view of community structure, with stochastic processes dominating deterministic ones (Sale's lottery hypothesis), started a debate that continues in this book. New ideas about factors that limit population size, from the arrival of very few planktonic larvae at a reef (pre-recruitment limitation) to reef-based factors such as postrecruitment predation, challenge the assumptions of adult space limitation made by Sale and his predecessors. Just as Sale should be commended for his early questioning of ecological dogma, he should be congratulated on pulling together an excellent set of contributions. Compiling books on the ecology of a particular group of organisms is itself a bit of a lottery, but with this one Sale has hit the jackpot.

Christopher W. Petersen is at the College of the Atlantic, 105 Eden Street, Bar Harbor, Maine 04609, USA. 